\title{
INTERRATER RELIABILITY DAN INTERNAL CONSISTENCY PENGKAJIAN LUKA KAKI DIABETIK THE NEW DIABETIC FOOT ULCER ASSESSMENT SCALE (DFUAS) BERBASIS FOTO
}

\author{
Nurawaliah Rasyid ${ }^{1,2 凶}$, Saldy Yusuf ${ }^{1}$, Takdir Tahir ${ }^{1}$ \\ ${ }^{1}$ Program Studi Magister Ilmu Keperawatan Universitas Hasanuddin Makassar \\ ${ }^{2}$ RSUD H. A. Sulthan Daeng Radja Kabupaten Bulukumba
}

\author{
ARTICLE INFO \\ Article history \\ Submitted : 2018-08-04 \\ Revised : 2019-02-06 \\ Accepted : 2019-02-14
}

\section{Keywords:}

Diabetic Foot Ulcer

DFUAS Assessment Reliability

\begin{abstract}
Diabetic foot ulcers have a high prevalence that requires good management of care. One of them is by assessing diabetic foot wounds. Currently, there has been a review of diabetic foot healing footage of New Diabetic Foot Ulcer Assessment Scale (DFUAS) which has been tested for validity and photo-based reliability. Nevertheless, in the DFUAS Assessment Reliability Test, there are still differences in perceptions on several DFUAS assessment variables on wound nurses. One reason is that there is no socialization given to the wound nurses on how to assess the DFUAS assessment. In addition, the previous DFUAS assessment reliability test is only performed on certified wound nurses whereas in health care services in patients with diabetic foot injuries are also performed by non-certified general nurses. This study aims to assess the interrater reliability and internal consistency of DFUAS-based on photo assessment on expert nurses and general nurses. The design of this study was cross sectional study. The samples in this study were certified nurses with ETN, CWCC, CWCCA and general non-certified Nurses with more than 2 years experience of wound care. The nurse as an observer evaluated 8 wounded images divided according to the wound stage (necrotic, slough, granulation and epithelial) using DFUAS assessment. Interrater reliability was assessed by spearman rho while internal consistency was assessed by cronbach's alpha. Interrater reliability shows good correlation with spearman rho> 0.60 . Internal consistency shows good reliability between DFUAS assessment items and Cronbach's alpha 0.98. This study shows that the DFUAS assessment is reliable on different nurses both certified nurses and general nurses.
\end{abstract}

Corresponding Author:

\section{Nurawaliah Rasyid}

Program Studi Magister Ilmu Keperawatan Universitas Hasanuddin Makassar

Telp. 085299820883

Email: awaliahnur08@gmail.com

\section{PENDAHULUAN}

Luka kaki diabetik (LKD) merupakan salah satu komplikasi yang terjadi pada pasien Diabetes Mellitus (DM) (International Diabetes Federation, 2017). Prevalensinya bervariasi antara $3 \%$ di Oceania sampai $13 \%$ di Amerika Utara dengan prevalensi ditingkat global ratarata $6,4 \%$ (Zhang et al., 2017). Demikian pula di Indonesia Timur, prevalensi luka LKD sekitar $12 \%$ (Yusuf et al., 2016). Tingginya prevalensi LKD dapat meningkatkan morbiditas, mortalitas serta kejadian amputasi yang menyebabkan penurunan kualitas hidup penderita DM (Costa, R, H, Cisneros, \& Luz,
2017). Oleh karena itu dibutuhkan manajemen luka yang baik mulai dari pengkajian sampai perawatan luka.

Pengkajian merupakan kegiatan pertama dalam proses keperawatan yang akan mempengaruhi proses keperawatan yang lain. Pengkajian dapat membantu perawat membuat pertimbangan klinis tentang kondisi pasien dan rencana tindakan selanjutnya (Weber \& Kelley, 2010). Dalam tatanan klinis, pengkajian LKD yang digunakan adalah Bates-Jansen Wound Assessment Tool (BWAT) untuk mengkaji status luka yang diakibatkan oleh berbagai macam penyebab serta karena adanya tekanan 
(Harris, Nancy, Rose, Mina, \& Ketchen, 2010). Namun BWAT pada dasarnya adalah pengkajian yang dibuat untuk menilai luka tekan atau dekubitus.

Saat ini telah dikembangkan pengkajian khusus LKD yaitu The New Diabetic Foot Ulcer Assessment Scale (DFUAS) yang dibuat khusus untuk menilai status LKD dari waktu ke waktu. Pengkajian ini dibuat sesuai dengan karakteristik luka pasien di Indonesia serta telah diuji validitas dan reliabilitas berbasis foto (Arisandi et al., 2016., Hasniati, Yusuf, \& Patellongi, 2017), termasuk reliabilitas foto diantara perawat luka (Muchtar, Sari, \& Yusuf, 2018). Meskipun demikian pada uji reliabilitas pengkajian DFUAS masih terdapat perbedaan persepsi pada beberapa variabel pengkajian DFUAS pada perawat luka. Salah satu penyebabnya adalah karena tidak adanya sosialisasi yang diberikan pada perawat luka tentang cara penilaian pengkajian DFUAS ini. Selain itu uji reliabilitas pengkajian DFUAS sebelumnya hanya dilakukan pada perawat luka tersertifikasi saja sedangkan ditempat pelayanan kesehatan perawatan pada pasien dengan luka kaki diabetik juga dilakukan oleh perawat general non sertifikasi (Muchtar et al,2018). Tujuan dari penelitian ini adalah untuk menilai interrater reliability dan internal consistency pengkajian DFUAS berbasis foto pada perawat ahli dan perawat general.

\section{METODE PENELITIAN Jenis Penelitian}

Jenis penelitian yang digunakan adalah penelitian analitik dengan desain cross sectional.

\section{Lokasi dan Waktu Penelitian}

Penelitian ini dilaksanakan di RSUP Wahidin Sudirohusodo Makassar tanggal 18 April 2018.

\section{Populasi dan Sampel}

Populasi dalam penelitian ini adalah perawat di wilayah Provinsi Sulawesi Selatan. Teknik sampling yang digunakan adalah quota sampling (Notoatmojo, 2010). Sampel dalam penelitian ini adalah perawat luka tersertifikasi serta perawat general non sertified dengan kriteria inklusi pendidikan terakhir minimal D3 Keperawatan, pengalaman merawat luka $>$ dari 2 tahun dan bersedia menjadi observer. Besar sampel dalam penelitian ini adalah perawat luka dengan kompetensi ETN sebanyak 2 orang,
CWCC 2 orang, CWCCA 3 orang dan perawat general non sertified sebanyak 2 orang.

\section{Pengumpulan Data}

Perawat sebagai observer melakukan penilaian terhadap 8 foto luka yang dibagi berdasarkan stadium luka (nekrotik, slough, granulasi dan epitel) dengan menggunakan pengkajian DFUAS yang telah ditranslasi di Pusat Bahasa Universitas Hasanuddin Makassar (Hasniati et al., 2017). Sebelum pelaksanaan penelitian, peneliti memperoleh ethical clearance dari komite etik Fakultas Kedokteran Universitas Hasanuddin Nomor : 376/H4.8.4.5. 31/PP36-KOMETIK/2018.

Sebelum pelaksanaan penelitian, peneliti terlebih dahulu memberikan informed concent pada observer yang bersedia menjadi responden dan memberikan penjelasan tentang tujuan dan prosedur penelitian.

\section{Pengolahan dan Analisis Data}

Penilaian terhadap foto luka dilakukan dengan mengisi instrument pengkajian DFUAS yang dilakukan oleh perawat di uji reliabilitasnya. Interrater reliability dinilai dengan spearman rho sedangkan internal consistency dinilai dengan cronbach's alpha.

\section{HASIL PENELITIAN}

Tabel 1. menunjukkan umur rata-rata observer pada kegiatan sosialisasi $33.90( \pm 8.84)$ yang pada umunya berjenis kelamin laki-laki yaitu 5 orang $(55.5 \%)$, dengan pendidikan terakhir S1 yaitu sebanyak 6 orang $(66.6 \%)$, pengalaman merawat luka pada umumnya $\geq 5$ tahun sebanyak 5 orang $(55.5 \%)$. Hasil uji interrater reliability pengkajian DFUAS berdasarkan stadium luka dapat dilihat pada tabel 2.

Penilaian pengkajian DFUAS oleh perawat dengan kompetensi ETN pada stadium luka nekrotik memiliki korelasi yang baik dengan $r \quad 0.83-0.92$. Namun pada stadium luka slough terdapat korelasi yang kurang baik pada foto 3 dengan nilai $r$ 0.43. Pada stadium granulasi korelasinya baik 0.86-.94 sedangkan pada stadium epitel korelasinya sedang dengan nilai $\mathrm{r}$ 0.50-0.69. Untuk kompetensi CWCC, pada stasium nekrotik terdapat korelasi yang kurang baik pada foto 2 dengan nilai $\mathrm{r} 0.17$. Demikian pula pada stadium slough dan granulasi korelasinya kurang baik yaitu pada foto 4 dan 6 dengan nilai $r$ masing-masing 0.15 . 
Sedangkan pada stadium epitel korelasinya sedang dengan nilai $\mathrm{r}$ 0.50-0.60. Untuk penilaian pengkajian DFUAS pada kompetensi CWCCA dibagi menjadi 3 kelompok penilai. Pada kelompok CWCCA 1 memiliki korelasi yang baik pada semua stadium luka dengan nilai r 0.63-0.97. Pada kelompok CWCCA 2 terdapat korelasi yang kurang baik pada stadium epitel dengan nilai r 0.39 yaitu pada foto 8. Pada kelompok CWCCA 3 juga terdapat korelasi yang kurang baik pada stadium slough dengan nilai $\mathrm{r} 0.39$ yaitu pada foto 4 . Pada kelompok perawat general menunjukkan korelasi yang kurang baik pada foto 4 dengan nilai $\mathrm{r}$ 0.28. Namun secara total terdapat korelasi yang sangat baik antara perawat general.

Pada tabel 3. menunjukkan bahwa instrumen DFUAS reliabel diantara perawat (observer) yang berbeda dengan nilai cronbach's alpha (0.98) yang berarti reliabilitasnya sangat baik. Variabel untuk kedalaman, ukuran, penilaian ukuran, peradangan/infeksi, perbandingan jaringan granulasi, jenis jaringan nekrotik, perbandingan jaringan nekrotik, perbandingan slough, maserasi dan tipe tepi luka memiliki reliabilitas sangat baik diantara beberapa perawat (observer) dengan nilai cronbach's alpha $>0.80$ sedangkan variabel tunneling memiliki reliabilitas sedang karena memiliki nilai cronbach's alpha 0.47 .

Tabel 1. Gambaran Karakteristik Demografi Observer

\begin{tabular}{|c|c|c|}
\hline \multirow{2}{*}{$\begin{array}{c}\text { Karakteristik } \\
\text { Demografi }\end{array}$} & \multicolumn{2}{|c|}{ Total } \\
\hline & $\mathbf{n}=\mathbf{1 0}$ & $\%$ \\
\hline $\begin{array}{l}\text { Usia (Tahun) } \\
\text { (Mean } \pm \text { SD) }\end{array}$ & 33.90 & $\pm 8,84$ \\
\hline Jenis Kelamin & & \\
\hline Laki-laki & 5 & 55,5 \\
\hline Perempuan & 4 & 44,5 \\
\hline Pendidikan terakhi & & \\
\hline D3 & 2 & 22,2 \\
\hline S1 & 6 & 66,6 \\
\hline $\mathrm{S} 2$ & 1 & 11,2 \\
\hline Lama Rawat Luka & & \\
\hline$<5$ tahun & 4 & 44,5 \\
\hline$\geq 5$ tahun & 5 & 55,5 \\
\hline Kompetensi & & \\
\hline ETN & 2 & 22,2 \\
\hline CWCC & 2 & 22,2 \\
\hline CWCCA & 3 & 33,4 \\
\hline General & 2 & 22,2 \\
\hline
\end{tabular}

Tabel 2. Interrater Reliability Pengkajian DFUAS berdasarkan Stadium Luka

\begin{tabular}{|c|c|c|c|c|c|c|c|}
\hline \multirow{2}{*}{$\begin{array}{c}\text { Stadium } \\
\text { Luka }\end{array}$} & \multirow{2}{*}{ Kasus } & \multicolumn{6}{|c|}{ Spearman Rho (r) } \\
\hline & & ETN & CWCC & CWCCA 1 & CWCCA 2 & CWCCA 3 & General \\
\hline \multirow[t]{2}{*}{ Nekrotik } & Foto 1 & 0.92 & 0.79 & 0.97 & 0.59 & 0.65 & 0.93 \\
\hline & Foto 2 & 0.83 & 0.17 & 0.86 & 0.61 & 0.67 & 0.86 \\
\hline \multirow[t]{2}{*}{ Slough } & Foto 3 & 0.43 & 0.79 & 0.79 & 0.75 & 0.95 & 0.96 \\
\hline & Foto 4 & 0.94 & 0.15 & 0.90 & 0.51 & 0.39 & 0.28 \\
\hline \multirow[t]{2}{*}{ Granulasi } & Foto 5 & 0.91 & 0.57 & 0.73 & 0.90 & 0.92 & 0.82 \\
\hline & Foto 6 & 0.86 & 0.15 & 0.91 & 0.77 & 0.81 & 0.61 \\
\hline \multirow[t]{3}{*}{ Epitel } & Foto 7 & 0.50 & 0.60 & 0.81 & 0.57 & 0.63 & 0.81 \\
\hline & Foto 8 & 0.69 & 0.50 & 0.63 & 0.39 & 0.73 & 0.76 \\
\hline & Total & 0.99 & 0.66 & 0.95 & 0.98 & 0.97 & 0.97 \\
\hline
\end{tabular}

\section{PEMBAHASAN}

Berdasarkan hasil penelitian menunjukkan bahwa secara total pengkajian DFUAS pada perawat yang berbeda memiliki reliabilitas yang baik. Meskipun demikian masih terdapat perbedaan penilaian baik pada kompetensi ETN, CWCC, CWCCA dan perawat general. Pada penelitian Forsythe, Ozdemir, Chemla, Jones, \& Hinchliffe (2016) melihat reliabilitas sistem klasifikasi PEDIS,
UT dan SINBAD dimana reliabilitasnya hampir sempurna ketika tiap observer menilai luka yang sama. Dalam penelitian ini semua observer dengan kompetensi yang berbeda melihat luka yang sama. Namun jika dilihat korelasi antara perawat yang berbeda tetapi memiliki kompetensi yang sama menunjukkan korelasi penilaian yang rendah pada beberapa stadium luka dan foto luka. Hal ini disebabkan karena adanya perbedaan pengalaman dari tiap 
perawat meskipun memiliki kompetensi yang sama. Penelitian Zhong et al., (2013) menunjukkan pengalaman merawat luka juga mempengaruhi kemampuan seseorang dalam memberikan penilaian terhadap luka dimana pada penelitian ini nilai reliabilitas observer yang berpengalaman lebih tinggi daripada staf biasa (ICC untuk staf biasa memiliki reliabilitas sedang sedangkan staf berpengalaman memiliki reliabilitas yang baik).

Untuk korelasi antar variabel pada pengkajian DFUAS dinilai dengan internal consistency menggunakan cronbach's alpha. Dari hasil penelitian menunjukkan bahwa tiap variabel pengkajian DFUAS menunjukkan reliabilitas yang sangat baik kecuali variabel tunneling memiliki reliabilitas sedang. Pada penelitian Muchtar, Sari, \& Yusuf, (2018) tentang reliabilitas pengkajian DFUAS antar perawat luka menunjukkan penilaian tunneling memiliki reliabilitas yang baik. Dalam penelitian ini, pada foto luka yang ditampilkan tidak disebutkan ukuran tunneling pada tiap gambar sehingga tunneling tidak dapat dikaji melalui foto.

Tabel 3. Internal Consistency Instrumen DFUAS

\begin{tabular}{lcc}
\hline \multicolumn{1}{c}{ DFUAS } & n & $\begin{array}{c}\text { Cronbach's } \\
\text { Alpha }\end{array}$ \\
\hline Kedalaman & 9 & 0.89 \\
Ukuran & 9 & 0.98 \\
Penilaian Ukuran & 9 & 0.98 \\
Peradangan & 9 & 0.95 \\
Perbandingan Jaringan Granulasi & 9 & 0.88 \\
Jaringan Nekrotik & & \\
$\quad$ Jenis Jaringan Nekrotik & 9 & 0.97 \\
Perbandingan Jaringan Nekrotik & 9 & 0.93 \\
Perbandingan Slough & 9 & 0.93 \\
Maserasi & 9 & 0.91 \\
Tipe Tepi Luka & 9 & 0.91 \\
Tunneling & 9 & 0.47 \\
Total & 9 & 0.98 \\
\hline
\end{tabular}

Pengkajian DFUAS merupakan pengkajian yang tergolong masih baru dan belum digunakan secara umum oleh perawat. Keterbatasan dalam penelitian ini adalah jumlah luka yang diobservasi tergolong sedikit begitu pula dengan jumlah observer yang terbatas.

\section{KESIMPULAN DAN SARAN}

Pengkajian DFUAS berbasis foto pada perawat yang berbeda baik yang tersertifikasi maupun general menunjukkan reiabilitas yang baik meskipun terdapat perbedaan penilaian pada beberapa stadium dan foto luka. Konsistensi internal dari variabel pengkajian DFUAS juga menunjukkan reliabilitas yang baik meskipun terdapat item tunneling yang tidak konsisten dalam mengukur variabel.

Penelitian ini menunjukkan masih dibutuhkannya latihan yang lebih intens pada perawat dalam penggunaan pengkajian DFUAS untuk mengevaluasi penyembuhan luka.
DAFTAR PUSTAKA

Arisandi, D., Yotsu, R. R., Masaru Matsumoto, Ogai, K., Nakagami, G., Tamaki, T., ... Junko Sugama. (2016). Evaluation of Validity of The New Diabetic Foot Ulcer Assessment Scale in Indonesia. Wound Repair and Regeneration, 24(5), 876884.

Costa, R, H, R., Cisneros, L. ., \& Luz, A. . (2017). Diabetic Foot. In: Navarro T., Dardik A., Junqueira D., Cisneros L. (eds) Vascular Diseases for the NonSpecialist. Springer, Cham. https://doi.org/https://doi.org/10.1007/97 8-3-319-46059-8_13

Forsythe, R. O., Ozdemir, B. A., Chemla, E. S., Jones, K. G., \& Hinchliffe, R. J. (2016). Interobserver Reliability of Three Validated Scoring Systems in the Assessment of Diabetic Foot Ulcers. 
https://doi.org/10.1177/15347346166545 67

Harris, C., Nancy, B. B., Rose, P., Mina, R., \& Ketchen, R. (2010). Bates-Jensen Wound Assessment Tool Pictorial Guide Validation Project, 37(June), 253-259.

Hasniati, Yusuf, S., \& Patellongi, I. J. (2017). Inter Rater Reliability Pengkajian Penyembuhan Luka Kaki Diabetes (The New Diabetic Foot Ulcer Assessment Scale) Berbasis Foto.

International Diabetes Federation. (2017). IDF Diabetes Atlas (Eighth edi). Retrieved from www.diabetesatlas.org

Muchtar, T. A., Sari, M., \& Yusuf, S. (2018). Interobserver Reliability of New Diabetic Foot Ulcer Assessment Scale in Indonesia: A Cross Sectional Based Pictures Study. Jurnal Luka Indonesia, 4(1), 24-29.

Notoatmojo, S. (2010). Metodologi Penelitian Kesehatan (Revisi). Jakarta: Rineka Cipta.
Weber, J., \& Kelley, J. H. (2010). Health Assessment in Nursing (4th ed.). Philadelpia: Lippicontt.

Yusuf, S., Okuwa, M., Irwan, M., Rassa, S., Laitung, B., Thalib, A., ... Sugama, J. (2016). Prevalence and Risk Factor of Diabetic Foot Ulcers in a Regional Hospital , Eastern Indonesia. Open Journal of Nursing, 6, 1-10.

Zhang, P., Lu, J., Jing, Y., Tang, S., Zhu, D., \& Bi, Y. (2017). Global epidemiology of diabetic foot ulceration: a systematic review and meta-analysis. Annals of Medicine, 49(2), 106-116. https://doi.org/10.1080/07853890.2016.1 231932

Zhong, S., Nagase, T., Huong, L., Kaitani, T., Iizaka, S., Yamamoto, Y., ... Sanada, H. (2013). Reliability and validity of the Chinese version of DESIGN-R, an assessment instrument for pressure ulcers. Oostomy/Wound Management, 59(2), 36-43. 